\title{
Renal Sympathetic Denervation and Quality of Life
}

\author{
Luciana Armaganijan ${ }^{1}$, Rodolfo Staico ${ }^{2}$, Aline Moraes ${ }^{3}$, Alexandre Abizaid $^{4}$, Dalmo Moreira ${ }^{5}$, \\ Celso Amodeo ${ }^{6}$, Marcelo Katz ${ }^{7}$, J. Eduardo Sousa ${ }^{8}$
}

\begin{abstract}
Background: Renal sympathetic denervation (RSD) is a promising strategy in the treatment of resistant hypertension. No studies have assessed the effect of RSD on quality of life in our country, which was the aim of this study. Methods: The EuroQol5 Dimensions questionnaire (EQ5D5L) was chosen to evaluate quality of life in 10 patients undergoing RSD, and it was applied before and 3 months after the procedure. Results: Mean age was $47.3 \pm 12$ years and $90 \%$ of the patients were female. Baseline blood pressure was $187 \pm 37.5 / 104 \pm 18.5$ $\mathrm{mmHg}$ and the number of antihypertensive drugs was 7.6 \pm 1.3 . Before the procedure, the value assigned to health status was $37.5 \pm 22.7$, increasing at 3 months to $70.5 \pm$ $20.9(\mathrm{P}=0.01)$. In the follow-up, in addition to a decrease in the number of antihypertensive drugs $(7.6 \pm 1.3$ vs. $6 \pm$ $2.2 ; \mathrm{P}=0.05)$, a trend towards reduced levels of systolic blood pressure $(187 \pm 36 \mathrm{mmHg}$ vs $170 \pm 44 \mathrm{mmHg} ; \mathrm{P}=$ $0.10)$ and diastolic blood pressure $(104 \pm 18 \mathrm{mmHg}$ vs $98 \pm$ $20 \mathrm{mmHg} ; \mathrm{P}=0.20$ ) was observed. Health status improvement resulted from a reduction of problems related to mobility, usual activities, pain/discomfort and anxiety/depression. The magnitude of blood pressure reduction was not associated with improved quality in all of the patients. On the other hand, those who had a decrease in the number of antihypertensive drugs reported a better health status. Conclusions: Patients with resistant hypertension have poor health status scores. RSD improved quality of life in most patients. Further studies are required to confirm consistent benefits.
\end{abstract}

DESCRIPTORS: Hypertension. Kidney. Sympathectomy. Quality of life.

\section{RESUMO}

\section{Denervação Simpática Renal e Qualidade de Vida}

Introdução: A denervação simpática renal (DSR) é estratégia promissora no tratamento da hipertensão arterial resistente. Nenhum estudo avaliou o efeito da DSR na qualidade de vida em nosso meio, objetivo deste estudo. Métodos: $O$ questionário EuroQol-5 Dimensions (EQ5D5L) foi utilizado para avaliar a qualidade de vida de 10 pacientes submetidos a DSR, sendo aplicado antes e 3 meses após o procedimento. Resultados: A média de idade foi de $47,3 \pm 12$ anos e $90 \%$ dos pacientes eram do sexo feminino. A pressão arterial basal foi de 187 $\pm 37,5 / 104 \pm 18,5 \mathrm{mmHg}$ e o número de antihipertensivos utilizados foi de $7,6 \pm 1,3$. Antes do procedimento, o valor atribuído ao estado de saúde foi de 37,5 $\pm 22,7$, aumentando aos 3 meses para 70,5 $\pm 20,9(P=0,01)$. No seguimento, além da diminuição do número de antihipertensivos $(7,6 \pm 1,3$ vs. $6 \pm 2,2 ; P=0,05)$, foi observada tendência a queda dos níveis da pressão sistólica $(187 \pm 36 \mathrm{mmHg}$ vs. $170 \pm 44 \mathrm{mmHg}$; $\mathrm{P}=0,10)$ e da pressão diastólica $(104 \pm 18 \mathrm{mmHg}$ vs. $98 \pm$ $20 \mathrm{mmHg} ; \mathrm{P}=0,20)$. A melhora do estado de saúde resultou da redução de problemas relacionados a mobilidade, atividades usuais, dor/desconforto e ansiedade/depressão. A magnitude da redução da pressão arterial não se associou à melhora da qualidade de vida em todos os pacientes. Por outro lado, aqueles que experimentaram redução do número de antihipertensivos relataram melhor estado de saúde. Conclusões: Hipertensos resistentes apresentam baixos escores de estado de saúde. A DSR apontou melhora da qualidade de vida na maioria dos pacientes. Estudos maiores são necessários para confirmar benefícios consistentes.

DESCRITORES: Hipertensão. Rins. Simpatectomia. Qualidade de vida.

\footnotetext{
${ }^{1}$ Cardiologist physician at the Electrophysiology and Heart Arrythmias Medical Section of Instituto Dante Pazzanese de Cardiologia. São Paulo, SP, Brazil. Fellow in research at the Masters of Health Sciences in Clinical Research program of Duke University (Durham, Estados Unidos). ${ }^{2}$ Doctor. Interventionist cardiologist physician at the Invasive Cardiology Service of Instituto Dante Pazzanese de Cardiologia. São Paulo, SP, Brazil. ${ }^{3}$ Cardiologist physician at the Section of Arterial Hypertension and Nephrology of Instituto Dante Pazzanese de Cardiologia. São Paulo, SP, Brazil.

${ }^{4}$ Full professor. Director of the Invasive Cardiology Service of Instituto Dante Pazzanese de Cardiologia. São Paulo, SP, Brazil.

${ }^{5}$ Doctor. Head of the Electrophysiology and Heart Arrythmias Medical Section of Instituto Dante Pazzanese de Cardiologia. São Paulo, SP, Brazil.
}

\footnotetext{
${ }^{6}$ Doctor. Head of the Section of Arterial Hypertension and Nephrology of Instituto Dante Pazzanese de Cardiologia. São Paulo, SP, Brazil. ${ }^{7}$ Doctor. Physician at Instituto Brasileiro de Pesquisa Clínica. São Paulo, SP, Brasil. Fellow in research at the Masters of Health Sciences in Clinical Research program of Duke University (Durham, Estados Unidos). ${ }^{8}$ Full professor. Director of the Center of Interventions in Heart Structural Diseases of the Instituto Dante Pazzanese de Cardiologia. São Paulo, SP, Brazil.
}

Correspondence to: Luciana Armaganijan. Av. Dr. Dante Pazzanese 500 - Vila Mariana - São Paulo, SP, Brazil - CEP 04012-180 E-mail: luciana_va@hotmail.com

Received on: 1/15/2013 • Accepted on: 3/5/2013 
$\mathrm{T}$ he prevalence of resistant hypertension ranges from $10 \%$ to $15 \%$, depending on the population studied and the applied definitions. Higher figures are observed in conditions associated with sympathetic hyperactivity, such as obesity, obstructive sleep apnea, diabetes, and renal dysfunction. Chronic arterial hypertension is associated with a substantial risk of stroke, coronary artery disease, and vascular disorders. In patients aged 40 to 70 years, each increment of $20 \mathrm{mmHg}$ in systolic blood pressure or of $10 \mathrm{mmHg}$ in diastolic blood pressure doubles the risk of cardiovascular disease in the range of blood pressure values between 115/75 mmHg and 185/115 mmHg. ${ }^{1}$ Studies indicate that hypertension is associated with worse quality of life.,.$^{2,3}$

Recently, the Symplicity-HTN2 Trial study demonstrated significant reduction in blood pressure (BP) in drug-resistant hypertensive patients submitted to renal sympathetic denervation. ${ }^{4}$ However, data regarding the safety, long-term effectiveness, reduction in the number of antihypertensive drugs, cost-effectiveness ratio, and effects on quality of life were not evaluated, especially in the Brazilian population. This study aimed to evaluate the effects of the experience with renal sympathetic denervation on the quality of life in patients with drugresistant hypertension in a tertiary center.

\section{METHODS}

\section{Population}

The study included patients submitted to renal sympathetic denervation who met the inclusion criteria: age between 18 and 80 years; systolic blood pressure measured at the clinic $>160 \mathrm{mmHg}$ despite treatment with at least three antihypertensive drugs; blood pressure controlled with at least four antihypertensive drugs; and favorable anatomy to renal sympathetic denervation determined by renal angiography. Exclusion criteria were: secondary hypertension; creatinine clearance $<45 \mathrm{~mL} / \mathrm{min}$; severe liver disease; New York Heart Association (NYHA) functional class III-IV heart failure or ejection fraction $<35 \%$; renal artery anomalies, such as stenos is $>50 \%$, presence of stent, or previous angioplasty; renal artery diameter $<4 \mathrm{~mm}$, and/or length $<20 \mathrm{~mm}$; pregnancy; life expectancy $<1$ year; or inability to complete follow-up requirements. An informed consent was obtained in all cases, and the study was approved by the local ethics committee.

\section{EuroQol-5 Dimensions Questionnaire}

The EuroQol-5 Dimensions (EQ5D5L), a questionnaire developed by the EuroQol group, aims at assessing health status, in a simple and generic way, and thus helping in the clinical assessment and implementation of economic measures. ${ }^{5}$ Applicable to a wide variety of health conditions, the EQ-5D-5L does not require a high cognitive level and can be performed in a few minutes.

The tool considers each domain independently and does not produce a total score of quality of life, considering the premise that quality of life is a multidimensional construct. It consists of two pages and includes two main components: a descriptive system that defines the health-related quality of life (HRQoL) in five dimensions (mobility, self-care, usual activities, pain/discomfort, and anxiety/depression), each with five levels of severity (1, no problems; 2 , some problems; 3 , moderate problems; 4 , severe problems; and 5, extreme problems), and a visual analog scale (VAS), in which patients indicate how they feel on a scale of 0 to 100 , where 0 represents the worst imaginable and 100 the best imaginable health, and the value is written in a box placed next to the scale (Figure 1). Patients are then classified with distinct five-digit health codes. ${ }^{5}$ For instance, state 11111 indicates no problems in any dimensions, whereas state 55555 shows extreme problems in all dimensions, and state 12345 shows no problems in mobility, some problems in self-care, moderate problems related to usual activities, severe problems regarding pain/discomfort, and extreme problems regarding anxiety/depression.

\section{Statistical Analysis}

Continuous variables were described as mean and standard deviation, and categorical variables as absolute and relative frequencies. The comparison of continuous variables was performed by paired Student's t-test, considering the pre- and post-procedure values. P-values $<0.05$ were considered statistically significant. STATA 11 SE software was used for statistical analysis and chart construction.

\section{RESULTS}

In total, ten patients (age $47.3 \pm 12$ years, 90\% women) underwent renal sympathetic denervation at the Instituto Dante Pazzanese de Cardiologia (São Paulo, SP, Brazil) between July and November 2012. Basal BP was $187 \pm 37.5 / 104 \pm 18.5 \mathrm{mmHg}$, and the mean number of antihypertensive drugs was 7.6 \pm 1.3 (ranging from five to nine). The mean time of hypertension diagnosis was $18.3 \pm 10.6$ years. All patients completed the questionnaire prior to the procedure and at three months of follow-up. The questionnaire was administered in-person by a specialist in hypertension. At three months, there was a tendency of BP reduction: systolic blood pressure pre vs. Post $(187 \pm 36 \mathrm{mmHg}$ vs. $170 \pm 44 \mathrm{mmHg}$; $\mathrm{P}=0.10)$, and diastolic blood pressure pre vs. post $(104 \pm 18 \mathrm{mmHg}$ vs. $98 \pm 20 \mathrm{mmHg} ; \mathrm{P}=0.20)$; $\mathrm{a}$ significant decrease in the number of antihypertensive drugs pre vs. post $(7.6 \pm 1.3$ drugs vs. $6 \pm 2.2$ drugs; $P=0.05)$ was also observed. 


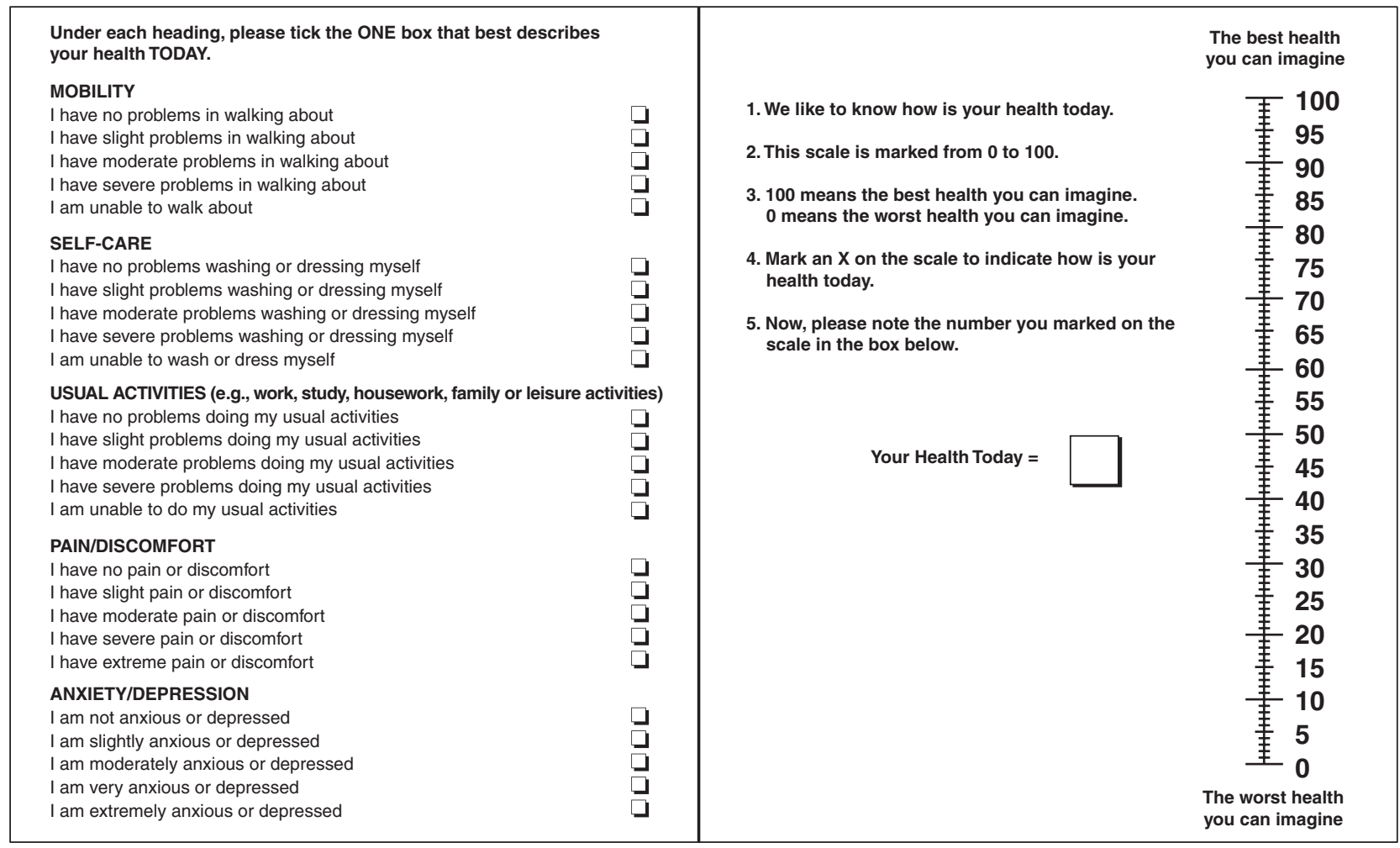

Figure 1 - EuroQOL-5 Dimensions score. To the left, the descriptive system that defines the health-related quality of life in five dimensions (HRQoL) and to the right, the visual scale in which the patients indicate the perception of their health status (Visual Analog Scale - VAS).

Before and after the procedure, 20 different combinations of values assigned to the dimensions were obtained. No patients showed absence of problems in all dimensions, nor extreme problems with self-care, performing usual activities, or pain/discomfort. Of the five analysed dimensions, extreme problems were only observed regarding mobility and anxiety/depression, whereas self-care was reportedby most patients as causing noproblems. Two patients reported extreme anxiety or depression before the procedure, and in one, there was no improvement during follow-up. There was improvement in the degree of anxiety/depression in four patients, in four other patients this dimension remained unchanged, and two patients reported a worsening of the condition (Table 1).

Before the procedure, the mean subjective health status was $37.5 \pm 22.7$, with significant improvement at three months $(70.5 \pm 20.9 ; \mathrm{P}=0.01)$ (Figures 2 and 3$)$. The health status improvement was the result of a decrease in problems related to the dimensions of mobility, usual activities, pain/discomfort, and anxiety/depression. The magnitude of the decrease in BP was not associated with an improvement in quality of life in all patients. Conversely, those who experienced reduction in the number of antihypertensive drugs reported improved health status after renal sympathetic denervation.

\section{DISCUSSION}

Renal sympathetic denervation was first employed in the treatment of resistant hypertension in the late 1930s. The procedure consisted in splanchnicectomy with sympathectomy, both thoracic and lumbar, associated with celiac ganglionectomy. Despite the promising results, frequent and disabling adverse events such as orthostatic hypotension, sphincter incontinence, sexual dysfunction, and paroxysmal excessive sweating werethe main limitations of this strategy. Hoobler et al. ${ }^{6}$ and Smithwick and Thompson ${ }^{7}$ demonstrated significant reductions in BP levels in up to $45 \%$ of patients between the first and fifth years post-sympathectomy. Hoobler et al. ${ }^{6}$ reported improvement of symptoms such as headache, dizziness, irritability, and nervousness that were disproportionate to the $\mathrm{BP}$ reduction, and satisfaction was reported by $95 \%$ of patients submitted to the surgery. Crile ${ }^{8}$ demonstrated that, in addition to the effects on BP, celiac ganglionectomy is associated with reduction in nervousness, fatigue, and irritability in $78 \%$ of cases.

The results of the present study indicate that patients with drug-resistant hypertension have substantial reduction in quality of life. In this small series of cases, many aspects improved after renal sympathetic denervation, 
Table 1

Proportion of patients before and after renal sympathetic denervation, for each dimension of the EQ-5D-5L questionnaire

\begin{tabular}{|c|c|c|c|c|c|c|c|c|c|c|}
\hline & \multicolumn{2}{|c|}{$\begin{array}{l}\text { Mobility } \\
(\%)\end{array}$} & \multicolumn{2}{|c|}{$\begin{array}{c}\text { Self-care } \\
(\%)\end{array}$} & \multicolumn{2}{|c|}{$\begin{array}{c}\text { Usual activities } \\
(\%)\end{array}$} & \multicolumn{2}{|c|}{$\begin{array}{c}\text { Pain/discomfort } \\
(\%)\end{array}$} & \multicolumn{2}{|c|}{$\begin{array}{c}\text { Anxiety/depression } \\
(\%)\end{array}$} \\
\hline & Pre & Post & Pre & Post & Pre & Post & Pre & Post & Pre & Post \\
\hline No problem & 0 & 20 & 70 & 70 & 20 & 40 & 20 & 20 & 10 & 10 \\
\hline Some problems & 20 & 30 & 30 & 30 & 30 & 30 & 40 & 40 & 20 & 40 \\
\hline Moderate problems & 50 & 20 & 0 & 0 & 40 & 10 & 10 & 30 & 30 & 10 \\
\hline Severe problems & 20 & 20 & 0 & 0 & 10 & 20 & 30 & 10 & 20 & 30 \\
\hline Extreme problems & 10 & 10 & 0 & 0 & 0 & 0 & 0 & 0 & 20 & 10 \\
\hline
\end{tabular}

EQ-5D-5L, EuroQol5 Dimensions.

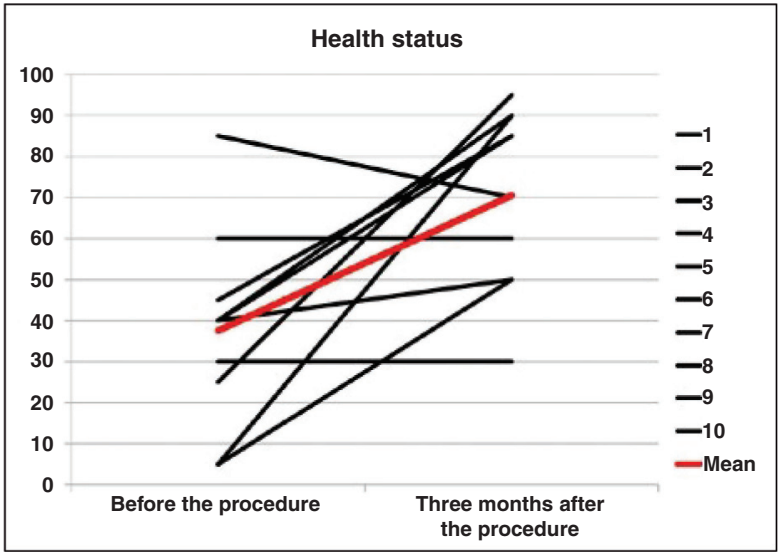

Figure 2 - Comparison of the health status before and after renal sympathetic denervation. The black lines correspond to the health status of each patient, and the red line represents the mean value.

such as reduction in problems related to mobility, usual activities, pain/discomfort, and anxiety/depression dimensions. It is noteworthy that the improvement in quality of life was not associated with the degree of improvement in BP levels in all patients. Conversely, those who experienced a decrease in the number of antihypertensive drugs reported better health status. In spite of the small population sample, an absence of response to renal sympathetic denervation was observed in $20 \%$ of cases, which is consistent with literature data. ${ }^{2}$ The two patients who did not have a reduction in BP levels or the number of medications were those who maintained unchanged health status after renal sympathetic denervation. One patient reported worsening of health status resulting from increased level of anxiety consequent to personal problems. The present results are similar to those observed in the study by Lambert et al., ${ }^{9}$ in which 40 patients submitted to renal sympathetic

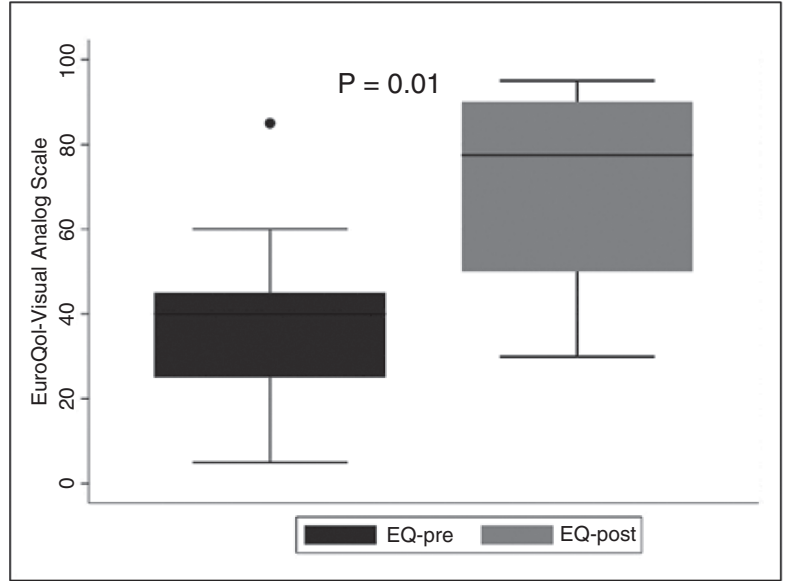

Figure 3 - Box plot demonstrating statistically significant difference in health status before and after renal sympathetic denervation. EQ, EuroQol.

denervation were assessed for quality of life through the SF36 questionnaire and the Beck Depression Inventory-Il after three months of follow-up. These authors showed reductions of $16 \pm 4 \mathrm{mmHg}$ and 6 $\pm 2 \mathrm{mmHg}$ in systolic and diastolic BP, respectively, and improved quality of life as a result of increased vitality, social function, and emotional and mental health, as well as reduced symptoms of sadness and fatigue, and improved libido. The magnitude of reduction in blood pressure levels was also not associated with changes in quality of life. ${ }^{9}$

In rats with chronic renal failure, afferent renal sympathetic denervation prevented the development of hypertension and elevation of norepinephrine in the posterior and lateral hypothalamic nuclei, and in the locus ceruleus. ${ }^{10}$ The highest concentration of norepinephrine is located in the locus ceruleus, 
which, together with the hypothalamus, influences the behavioral responses. ${ }^{11,12}$ The biological effects of renal sympathetic denervation on quality of life, however, are still indeterminate and deserve further trials.

Despite not reaching statistical significance, probably due to the small number of patients and/or less marked decrease in blood pressure levels due to the concomitant decrease in the number of antihypertensive drugs, significant improvement of health status was observed, demonstrating that the benefits of renal sympathetic denervation may extend beyond blood pressure control.

\section{Study limitations}

Some limitations should be noted. First, quality of life assessment is subjective and may indicate individual opinions rather than the actual health status of the individual. Moreover, it can vary over time in the same patient, depending on the circumstances concerned and priorities, which constitutes a limitation of questionnaires used to assess quality of life. Second, variables such as socioeconomic status, education, and age were not correlated to the findings and could have had an effect on the observed results. Third, the possible placebo effect of the procedure may confound result interpretation. Finally, the small sample size is an important limitation of this case series.

\section{CONCLUSION}

In this small case series, it was observed that adults with resistant hypertension have low scores for health status and unsatisfactory quality of life for most domains of the EQ-5D-5L questionnaire. Comparison of outcomes after renal sympathetic denervation showed improvement in quality of life in most patients. Larger studies are required to confirm consistent benefits.

\section{CONFLICT OF INTEREST}

The authors declare no conflicts of interest.

\section{REFERENCES}

1. Lewington S, Clarke R, Qizilbash N, Peto R, Collins R; Prospective Studies Collaboration. Age specific relevance of usual blood pressure to vascular mortality: ameta analysis of individual data for one million adults in 61prospective studies. Lancet. 2002;360(9349):1903-13.

2. Mena Martin FJ, Martin Escudero JC, Simal Blanco F, Carretero Ares JL, Arzua Mouronte D, Herreros Fernandez V. Health related quality of life of subjects with known and unknown hypertension: results from the population based Hortega study. J Hypertens. 2003;21(7):1283-9.

3. Hayes DK, Denny CH, Keenan NL, Croft JB, Greenlund KJ. Health related quality of life and hypertension status, awareness, treatment, and control: National Heal thand Nutrition Examination Survey, 2001-2004. J Hypertension. 2008;26(4):641-7.

4. Esler MD, Krum H, Sobotka PA, Schlaich MP, Schmieder RE, Bohm M. Renal sympathetic denervationin patients with treatment resistanthy pretension (the Symplicity HTN-2 Trial): arandomised controlled trial. Lancet. 2010; 376(9756):1903-9.

5. The EuroQol Group. EuroQol a new facility for the measurement health related quality of life. Health Policy. 1990; 16(3):199-208.

6. Hoobler SW, Manning JT, Paine WG, Mc Clellan SG, Helcher PO, Renfert HJr, et al. The effects of splanchnicectomy on the blood pressure in hypertension: a controlled study. Circulation. 1951;4(2):173-83.

7. Smithwick RH, Thompson JE. Splanchnicectomy for essential hypertension; results in 1,266 cases. J Am Med Assoc. 1953; 152(16):1501-4.

8. Crile G. The clinical results of celiac ganglionectomy in the treatment of essential hypertension. Ann Surg. 1938;107(6):909-16.

9. Lambert GW, Hering D, Esler MD, Marusic P, Lambert EA, Tanamas SK, et al. Health related quality of life after renal denervation in patients with treatment resistant hypertension. Hypertension. 2012;60(6):1479-84.

10. Campese VM, Kogosov E. Renal afferent denervation prevents hypertension in rats with chronic renal failure. Hypertension. 1995;25(4Pt2):878-82.

11. Foote SL, Bloom FE, Aston Jones G. Nucleus locusceruleus: new evidence of anatomical and physiological specificity. PhysiolRev. 1983;63(3):844-914.

12. Svensson TH. Peripheral, autonomic regulation of locus coeruleusnor adrenergic neurons in brain: putative implications for psychiatry and psychopharmacology. Psychopharmacology. 1987;92(1):1-7. 